\title{
Internal and External Factors Analysis of Kenya Airways' Strategic Management: A Mini-Review
}

\author{
Bowen Liu', a, *, Mengyuan Chen", b, Wenli Zhou', c \\ ${ }^{1}$ School of International Business Management, Coventry University, Coventry CV1 5FB, United Kingdom \\ ${ }^{2}$ School of Tourism and Hospitality, Management Development Institute of Singapore, Singapore, 148951, Singapore



\begin{abstract}
This research is mainly to understand the business operation environment internally and externally which correlate with the Airline industry. It also aims to address various issues that affect the development of Kenya airways as an international airline operator. Such as the relationship of the airway with its host countries is also essential in determining the various barriers to a harmonious coexistence in its business strategy and development. There are also various issues of the company's internalization to countries which has not established its brand. For example, the Kenya Airways has no business in Australia, the reasons are also addressed in this paper and further recommendations are also given. All these developments and challenges plus the effects of the pandemic in the transport and logistic industry also take into the considerations into this research. There are various frameworks (Valuable, Rare, Inimitable, and Companyal Analysis and the PESTEL Analysis) which will help articulate the importance and the challenges of the business environment to the airline industry. The study uses different strategies to address different scenarios within the company; these strategies include functional, conceptual, corporate, and business-level strategies.
\end{abstract}

Keywords: Kenya Airways, Strategic Management, VRIO Analysis, PESTEL Analysis, International Development.

\section{Introduction}

Kenya Airways Airline is a Kenya-based air transport situated in the capital city of Kenya (Nairobi, 2021). The firm's relation to the internal and external business environment is critical and essential in analyzing the industry trends and the world market. The effects of the pandemic on the industry are also significant in understanding the importance of the firm's operations. Uncertainties are arising from the market due to current trends in the air transport sector and, therefore, the need to analyze both the industry's internal and external environment is outstanding.

Airline transportation is a key component in the efficiency of logistics to a country. Therefore, the challenges facing by one Airline may be correlated with the others if they share the same business environment. However, some specific challenges and issues are specific rather than generic (COVID-19 and economic challenges of the Exchange Rate in the world). The challenges can be internal or externa, both internal and external factors may affect the Airline's operation in one way or the other.

The analysis of the Airline through the VRIO framework makes a perfect analysis of the company's current condition and future trends and therefore mapping the company's specialty in the industry. This analysis ascertains the closeness of various competitors of the Kenya Airways in the industry and strategies competitive. The analysis has helped the company protect its resources and capabilities, providing its competitive advantages. The PESTEL analysis is also important in creating a correlative link between the external factors to the company while the company can be sustained through the internal environment at same time. The strategic management is an integrated approch that maps the company on promising performing grounds both for now and future, hence maintaining the company's competitiveness in the industry.

\section{Internal Factor Analysis of Kenya Airways}

Amankwah-Amoah, J. (2018) described these factors as the factors that affect the internal operation of the firm. The internal factors include Company-level factors, production factors, personnel factors, marketing factors, and financial factors. The management has total control of these factors and, therefore, can influence the performance level of these factors in the host country, which is the United States of America.

\subsection{Company-level Factors}

Different country has different business operation environment, culture and rules. As a foreign company which plan to enter the new country to develop its business needs to analyze these factors keenly and carefully. For example, the communication platform in the United States of America is very efficient and well developed, facilitating the company's operation smoothly with current trends. However, the company has to invest huge number of resources as the communication platform is quite expensive. The cost factors of the communication platform in the United States are meant to make the company forgoes the expenses and gain efficiency in communication factors. Airline's customers value instance feedback for orders and booking done through the transportation facility. A sluggish communication parameter will cost the firm more than it would cost to implement the communication equipment.

Still, other Company-level factors of the firm, such as Kenya Airways has departmental issues to address within the company. The internal rules and policies are also important as they coincide with the host countries regulatory authority. An emerging set of rules of the COVID-19 has to adhere as they differ from country to country. 


\subsection{Production Factor}

The production and service factor of the firm in the host country are also considered as internal factors. These factors relate to the transformation of services within the firm. These factors influence the Kenya Airways operation in the United States in different ways. The influence comes in the form of the airline equipment to be used and the investment limits to be done within the firm.

The United States has a strict adherence to the level of investment in the firm before the Insurance regulatory Authority starts sniffing on the firm's internal business. (Hugh Davies, 2021) The country's investment limits are fair and guarantee the firm's focus on their development factor in the host country. The availability of amiable and fair competition has also improved the sectors service output through a gauged experience of improving the firm's services in the host country; with recent openings of the direct flight, it is right to say there have been difficulties in meeting the market and the country' demand in the production and service delivery. However, the challenge imposed to this new firm settlement is a gauge of the industry's attainment of better service delivery and competitive strategy in the market.

The production factor of the firm also considers the equipment, or the vessel used in the market. There are concerns of Boeing's vessel often being at fault; despite their remarkable existence in the market and reasonable pricing of the vessels, the host country's restriction to use of such aircraft has challenged the Airline development in the host country. The United States is determined to safeguard the life of its citizen regardless of the cost; some airlines operating in the country may forgo this factor as long the customers' satisfactory needs are met, hence the strict need to facilitate the safety of the people through quality services and products are key consideration.

\subsection{Personnel Factor}

The personnel factor is also an internal factor that Kenya Airways addresses in the host country. This factor is the related to the employees, their promotion criteria, their welfare, and salaries. The United States has a wage bill that is reasonably higher than other countries. The wage bill dictates that the business has to generate enough income to certain itself in the market. The host country's minimum wage bill is at $\$ 7.25$ per hour; this shows that the higher and the more complex the firm's operation, the higher the wage bill of the personnel. The minimum wage bill factor is critical, as it motivates the employees to develop the firm's business in the host country.

The other personnel factor is the promotion factor. United States pride itself on the fairness of service and selection of qualified personnel to fill the vacancies in the market. The promotion factor may be due to the retirement of senior officers or new vacancies that create operational level opportunities for newbies due to the promotion of the existing staff. Any traces or suspicion of the unfair practices will affect the personnel factor of the firm in the host country.

There are also factors of welfare treatment among the employees. The welfare association in the host country is more inclined to the well-being of the staff rather than pay rise, this is through the State's economic development compared to the other developing countries.

\subsection{Marketing Factor}

The other internal factor that affects Kenya Airways in the
United States is the marketing factors of the country. The geolocation of the firm influences the marketing factors of the firm in terms of fees charged to do an advertisement and create awareness in the country. The issue of the pricing strategy has to be factored into accounts by the firm before extra expansion into various states of the USA.

A favorable pricing strategy influences how the market will be convinced of their services in the market. The more the customer is satisfied, the more they are likely to be convinced to use the Airline. Once the market is convinced of the firm's operation, the higher revenue generated.

\subsection{Financial Factor}

The final internal factor is the financial factor of the firm. The finances of the firm can be done effectively with the jurisdiction of the host state. The strength of their currency facilitates the effectiveness of raising funds required for the development of the firm. The availability of various financial institutions is also crucial in gathering the required amount of funds for the firm's operation in the host country.

The United States has a formidable and conducive environment that supports investment, and therefore, the time spent to facilitate a decision of investing the firm is shorter; less time in decision making guarantees a quicker response and therefore efficiency in customers' satisfaction.

\subsection{VRIO Analysis}

The VRIO analysis framework complements the PESTEL analysis by dictating the valuable assets within the company. The Kenya Airways' strategic management describes the valuables, rare, inimitable, and company assets of the firm.

There are various valuables within the company which including vessels, professional employees, availability of technology, the culture of the company in its operational aspects, capability and flexibility to fit into the dynamics of any situation presented to them by external factors and so on.

\section{External Factor (PESTEL) Analysis of Kenya Airways}

The external factors of the Kenya Airways are the factors that the firm has no jurisdiction in control. These factors exist outside the firm's business environment, and therefore the focus is on the United States environment affecting the firm. The external factors include social factors, technological factors, economic factors, ethical factors, political factors, legal factors, and ecological factors. To best understand the correlation analysis of the firm with the firm external environment PESTEL Analysis defines the environment in the best way. (Linden, 2021).

\subsection{Political Factor}

The first external factor, according to the PESTEL analysis, is the Political factor. Political factors are the factors that relate to the nature of the government of the host country. They include the ideology and policies governing the air transport by the government.

The best way to understand the changes is through a close analysis of the country's political affairs and their development factor in the political factors. The regulation that requires airlines to operate outside the central business districts of different cities is among the various political concerns of the country, and the Kenya Airways should consider and articulate their change in operation and 
development strategies accordingly.

\subsection{Economic Factor}

The second external factor, according to the PESTEL analysis, is the economic factor. The economic factor of the host country affects operations of the firm through their inflation rate; when the currency value reduces, the inflation rate increases, which means that the money diminishes its value in the development sector. The interest rate is also a factor in the economic factor of the firm, the amount of funds borrowed yields through the interest rate; when the interest rate is high in the host country, the Kenya Airways will reduce its burrowing in an attempt to reduce the expenditure levels of the country.

Another factor is the employment level; for instance, the employment rate in the United States is fair and therefore reducing the burden of the country income and borrowing; the firm also benefits from these factors as the country will not levy huge duties on their operation for balanced books of accounts at every financial period of the country.

There are other economic factors that relatively affect the firm in the host country this includes the consumer income, the level of consumer income affects the firm consumption rate in the market, this means the level of standards portrayed by customers project our future consumer rate in the market; the debt and expenditure behavior of the customers, this dictates the propensity and willingness of the consumer to use our services in the market due to their disposable income. These are the factors relating to the changes of the economy of the host state pertaining to their resources available in the country and their allocation to different firms running in their lands. The United States population has a better number of people living above the poverty line; the margin between those who are wealthier and those who are poor is seemingly low, hence a relief in the economic factors of the firm in the host country.

\subsection{Social Factor}

The social factor is also an external factor of the firm that dictates how the Kenya Airways relates within the broader society of the host country.

The society comprises demographic factors such as religion, lifestyle changes, gender, and workforce diversity. Kenya Airways operating in the United States should analyze the different changes in the society and ensure that they can embrace them positively. An introduction of a flexible work arrangement within the company will give the firm a better reputation in the society in the United States. These arrangements may include giving female workers leave when they are nursing their motherhood and establishing structures that cater to the disabled members of the society.

The other factor is the issue of gay people; since the Airline comes from a background that does not advocate gay people, the firm could easily fall prey to the diverse personality and gather criticism that may ruin their reputation in the market and reduce their overall revenue. The firm should conduct a thorough analysis of the dynamics of the society before making a cognitive decision for the firm in the host country.

Another factor of the firm operations due to technological advancement that does not require workers to be at the firm's premises, functions such as customer services can be handled at the comfort of the workers' home; the firm should consider this lifestyle changes in the society and implement a coercive approach towards its to avoid inconveniences caused by the gap between the firm and the society of the host country.

\subsection{Technological Factor}

Technological factors are also external factors that relate to the advancement in technology and the impact on the Kenya Airways operations in the host country.

The United States is considered to in the future according to air transport and facilities; their technology is more advanced than any other trying country. Kenya Airways has too much of this technology in their entire establishment to maintain relevance in the market. The technological aspects of the airlines in the United States shape the flying experience in the industry and therefore ted ty of the firm to develop these changes for a better consumer experience. Among the technologies is blockchain technology in the financial sector of airline operations. The use of augmented reality and virtual reality in the industry, the vast use of artificial intelligence, beacon technology, wearable technology, robots, and biometrics are pivotal for their Airline, especially the current situation with the cold warfare's between the host country and many other countries.

The implementation of these technology by Kenya Airways operating in the United States guarantees the State safety and smooth adherence to safety regulations of the Airline.

\subsection{Environmental Factor}

The environmental factor is related to broad ecological terms of weather and climatic changes in the country. The host country has been at the forefront in addressing the issues of global warming and the conservation of the environment; this aspect is a policy within the State for all the firms operating in the country.

Kenya Airways is expected to adhere to the environmental rules and regulations of green operation within the host country; this means that the vessel acquired should be a hybrid generation that consumes little fuel and emit less carbon to the environment. The current technology on ways to advance air vessels to rechargeable engines is currently underway; once the project is proven and tested, the Kenya Airways will be required to fit into the system of the country's transformation. The materials used in making the vessels of the Kenyan Airlines should also be disposable and harmless to the environment once they are scraped and needs to be disposed. (SAA, 2021)

\subsection{Legal Factor}

The Kenya Airways has to be updated on the current trend affecting the legal action of the industry. The legal factors of external factors are related to the laws that are cast in the host country (United States).

For example: with the COVID-19 pandemic ban for transportation of people more than half the required passengers was a legal offense, the legality was uplifted and revised to transportation of unvaccinated individuals became a legal offense. And there is another example of the period where all Boeing's vessels were banned from ferrying goods and services within the host country also impacted the Airline's services within the country.

Despite the recent direct flights and establishment of Kenya Airways in the United States, the firm should be quick to notice and make changes that are in line with the host country's legal requirements to avoid shutdown and loss of business within the country. The legality of purpose requires that the Airline obtain a verification certificate to ascertain the 
standards required by the host country.

\section{International Development of Kenya Airways}

\subsection{Privatization of Services}

The firm has not yet hit its target in its market development. Various quite specific issues have impeded the milestone projection of expansion and internalization of services. For instance, Kenya Airways has not been established in countries such as Australia and Iceland. According to Ndungu 2014), the effects that limit this expansion include corruption, embassies stiffness, and networking approaches by the home country. Since the home country runs the main operation, it is safe to observe corruption among the officials in the firm is impeding the process of development in the host state. The revenue gained goes into the pockets of individuals rather than the far allocation of resources for expansion criteria. (Oliver Clark, 2020) The stiffness between the two countries hoping to establish a bilateral agreement also contributes to the development slowdowns; the negations teams often engage in adversarial negation and therefore fail to reach an agreement. In the COVID era, most operations that include different countries have been done through online platforms. Lack of networking equipment in the home country has lessened the chances of attaining a common agreement; faceto-face communication can be resource-consuming and, therefore, reduce the chances of expansion. There are also generic problems to this cause being denied a chance, and they include the coronavirus pandemic and the terror attacks that are more likely to be linked by the home country. (Linden E., 2021)

\subsection{BAA's Eve Partners with Kenya Airways on the Future of Urban Air Transport}

Aviation Resources, 12 August 2021 - Eve has signed a Memorandum of Understanding ( $\mathrm{MoU}$ ) with Fahari Aviation, a wholly owned subsidiary of Kenya Airways, Kenya's flagcarrying airline. The partnership aims to develop an Urban Air Mobility (UAM) operating model to support Fahari Aviation's key markets. In addition, through this partnership both parties will work together to create the conceptual and programmatic basis for the safe deployment of an electric vertical take-off and landing (eVTOL) aircraft, also marketed as EVA (Electric Vertical Take-off and Landing Aircraft).

Eve will support Fahari Aviation, the unmanned aircraft systems (UAS) division of Kenya Airways, in the establishment of an urban air traffic network and collaborate on the development of the required Urban Air Traffic Management (UATM) procedures and urban air traffic operating environment. Through the partnership, Fahari Aviation will support the development of the Eve aircraft and products, which will also help advance the integration of urban air traffic with Kenya Airways' overall operations. (Linden E., 2021) The Eve all-electric aircraft is designed to provide connectivity to the general public, and it is also an environmentally friendly aircraft with low noise and zero emissions. This model is designed to significantly reduce the time spent on road traffic. It is ideally suited as a UAM aircraft, allowing all conventional air travelers to approach their final destination efficiently and comfortably. The partnership will provide strong strategic support to offer Fahari Aviation's passengers a sustainable, convenient, and affordable transport option. It is estimated that electric vertical take-off and landing aircraft can reduce the time taken to travel from the airport to the city centre by urban air transport by approximately $90 \%$ compared to traditional road transport, reducing an hour and a half drive to a six-minute flight.

\subsection{Kenya Airways Fleet to Double in Size in the Next Five Years}

Kenya Airways' plan for the next ten years has even made the coverage of every African country a key part of its route network development plan. Kenya Airways and Embraer had earlier agreed on a letter of intent for up to 10 more E-170s. The company currently operates two E-190s and five E-170s, with two new E-190s joining its expanding fleet by the end of this year, with deliveries starting next year and continuing until 201. The E-jet, with a passenger capacity of 1,000 passengers, is well suited to the expansion of KLM on its African feeder routes and new destinations. With the introduction of more E-jets, both passenger and cargo capacity will be expanded to address the large amount of luggage that passengers to Africa usually carry.

Kenya Airways has been linked to the purchase of nine Boeing Dreamliner from Boeing and is considering the purchase of an additional four aircraft. It is hoped that the new aircraft will help us to expand our routes and network. Kenya Airways also announced that from 1 October, it will operate a Boeing 777 luxury jumbo jet from Guangzhou and Hong Kong, with 28 business class and 294 economy class aircraft on board, increasing capacity by almost 50 per cent. The airline currently operates four flights from Guangzhou on 1 , 2 and 5, and one flight from Hong Kong on 4, 6 and 7 to Nairobi via Bangkok, with connections to 50 African destinations within an hour of Nairobi.

\section{Summary}

In conclusion, operation of airline business is a complex and expensive investment which may affect not only a company but a country's economy. But Airline investments are important to a country's economy as it is important for the country's political and economic activities and development. Two countries that plan to build closer interconnections need to learn from each other, collaborate with each other, and address internal and external factors through improving their business strategies to achieve better business success.

\section{References}

[1] Amankwah-Amoah, J. (2018). Why are so many African companies uncompetitive on the global stage? Insights from the global airline industry. In Africa's competitiveness in the global economy (pp. 195-216). Palgrave Macmillan, Cham.

[2] Congo Airways wet-leases two E190s from Kenya Airways. (2021). Airguide Business.

[3] Further snags for Kenya Airways' nationalisation plan. (2020). Airguide Business.

[4] Hugh Davies. (2021). Kenya Airways still requires state support - CEO. Airfinance Journal (Online).

[5] Kenya Airways, Congo Airways ink strategic partnership. (2021). Airguide Business.

[6] Kenya Airways' stock trading suspension extended. (2021). Airguide Business.

[7] Kenya Airways to save $\$ 45 \mathrm{mn}$ from new fleet lease terms. (2021). Airguide Business. 
[8] Kenyan parliament votes to nationalise Kenya Airways. (2019). African Business (Al Bawaba (Middle East) Ltd.).

[9] Lessors okay Kenya Airways use of two B787s as freighters. (2020). Airguide Business.

[10] Linden, E. (2021). Pandemics and environmental shocks: What aviation managers should learn from COVID-19 for long-term planning. Journal of Air Transport Management, 90, 101944.

[11] Miyoshi, \& Ibáñez, E. R. (2016). Are fuel-efficient aircraft worth investing in for non-Annex country airlines? An empirical analysis of Kenya Airways with an aircraft appraisal cost-benefit analysis model. Transport Policy, 47, 41-54.
[12] Nairobi preps bailout for Kenya Airways in 2022 budget. (2021). Airguide Business.

[13] Ndungu, J. W. (2014). Factors Influencing the Internationalization And Selection of Foreign Market Entry Modes of International Airlines Operating To And From Kenya (Doctoral dissertation, United States International University-Africa).

[14] Oliver Clark. (2020). Kenya Airways receives state loan. Airfinance Journal (Online).

[15] SAA, Kenya Airways plan pan-African airline group by 2023. (2021). Airguide Business. 